\title{
Analyzing the impact of conflictive dental characters on the phylogeny of octodontoid rodents
}

\author{
Adriana M. Candela \\ Acta Palaeontologica Polonica 61 (2), 2016: 455-468 doi:http://dx.doi.org/10.4202/app.00113.2014
}

Systematics of fossil octodontoids (Rodentia, Caviomorpha) is in great part based on insights into the knowledge of teeth, making the step of dental characterization certainly relevant for the evolutionary reconstruction of these rodents. Different homology hypotheses were proposed for the same tooth structures, a fact that indicates the importance of knowing on which criteria the dental characters supporting the classifications were based. In this line, I evaluate the step of characterization of certain conflictive molar characters previously used, and their impact on phylogeny of octodontoids. I explore which the criteria followed to propose the hypotheses of correspondences for these characters are in light of the anatomical evidence. Based on the outcome of phylogenetic trees obtained previously, I analyze if the evolutionary transformations are compatible with character states observed in the terminals. New cladistic analyses based on recoded molar characters indicate that, unlike results recently obtained, the unorthodox position of Sallamys, Protadelphomys, and Willidewu as basal ctenomyines is not recovered. The position of Caviocricetus, Acarechimys-Neophanomysas as Octodontinae is not maintained. These results indicate that reanalyses of conflictive dental characters, scrutinizing data matrices, are particularly necessary to evaluate the current controversy on the phylogeny of octodontoids. Lower molar character definition and character states delimitation in octodontoids, being relevant to phylogenetic reconstruction, should be founded on anatomical examination, following explicit criteria of homology. Alternative hypotheses of "primary homology" proposed for the same molar traits in octodontoids indicate that each main group of caviomorphs requires its own anatomical study.

Key words: Mammalia, Rodentia, Octodontidae, Echimyidae, homology, parsimony analysis, tooth morphology.

Adriana M. Candela [acandela@ fcnym.unlp.edu.ar], CONICET, División Paleontología Vertebrados, Museo de La Plata, Paseo del Bosque s/n, 1900 La Plata, Argentina. 
This is an open-access article distributed under the terms of the Creative Commons

Attribution License (for details please see creativecommons.org), which permits unrestricted use, distribution, and reproduction in any medium, provided the original author and source are credited.

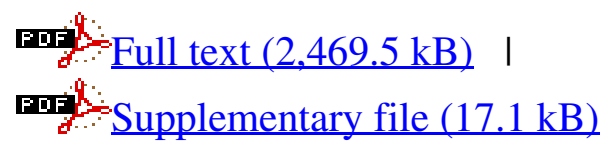

